\title{
Corrigendum
}

\section{Corrigendum to "An empirical comparison of machine learning techniques for dam behaviour modelling” [Struct. Saf. 56 (2015) 9-17]}

\section{F. Salazar ${ }^{\mathrm{a}, *}$, M.Á. Toledo $^{\mathrm{b}}$, E. Oñate ${ }^{\mathrm{a}, \mathrm{c}}$, R. Morán $^{\mathrm{b}}$}

${ }^{a}$ CIMNE - Centre Internacional de Metodes Numerics en Enginyeria, Campus Norte UPC, Gran Capitán s/n, 08034 Barcelona, Spain

${ }^{\mathrm{b}}$ Technical University of Madrid (UPM), Civil Engineering Department: Hydraulics, Energy and Environment, Profesor Aranguren s/n, 28040 Madrid, Spain

${ }^{\mathrm{c}}$ Universitat Politècnica de Catalunya (UPC), Barcelona, Spain

The authors wish to report an error in Fig. 1 of the above-mentioned article. The correct position of the monitoring devices is shown below.

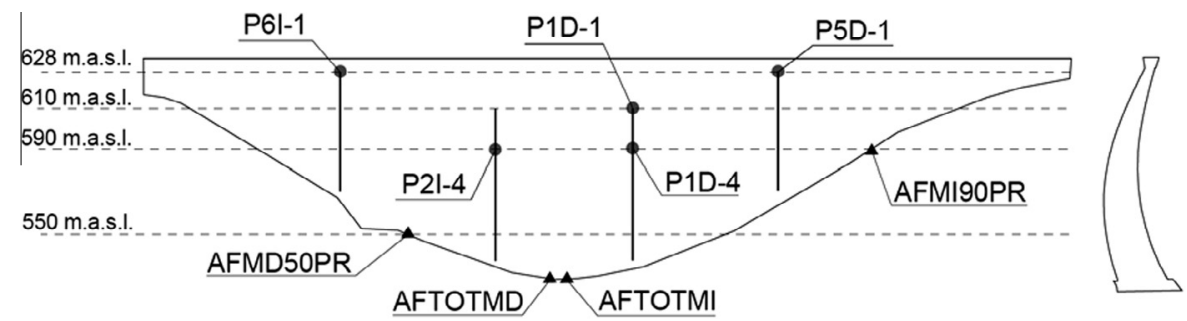

Fig. 1. Geometry and location of the monitoring devices in La Baells Dam. Left: view from downstream. Right: highest cross-section. 